Jurnal

Kardiologi Indonesia

J Kardiol Indones. 20I5;36:28-33

ISSN $0126 / 3773$

Case Report

\title{
Left Atrial Myxoma with Tricuspid Regurgitation: Pathophysiology, Diagnostic Approach, and Management
}

\author{
Prima Almazini, Bambang Budi Siswanto, Nani Hersunarti, Rarsari Soerarso, \\ Amiliana M Soesanto
}

Department of Cardiology and Vascular Medicine, Faculty of Medicine, Universitas Indonesia

National Cardiovascular Center Harapan Kita, Jakarta
Cardiac myxomas are the most common primary cardiac tumors. Myxoma are more common in women. Clinical manifestations can mimic many cardiac and noncardiac conditions. Transthoracic echocardiography (TTE) is the gold standard method in the diagnosis of cardiac myxoma. The management of cardiac myxoma are medical therapy for the treatment of associated conditions and surgical removal as the definitive treatment.

(J Kardiol Indones. 20I5;36:28-33)

Keywords: atrial myxoma, echocardiography, extirpation 


\title{
Myxoma Atrium Kiri dengan Regurgitasi Trikuspid: Patofisiologi, Diagnosis dan Tata Laksana
}

\author{
Prima Almazini, Bambang Budi Siswanto, Nani Hersunarti, Rarsari Soerarso, \\ Amiliana M. Soesanto
}

\begin{abstract}
Myxoma atrium kiri adalah tumor jinak jantung yang paling banyak ditemui. Myxoma atrium kiri paling banyak terjadi pada perempuan. Presentasi klinis myxoma atrium kiri dapat menyerupai berbagai macam penyakit baik kardiak maupun nonkardiak. Ekokardiografi merupakan modalitas diagnostik baku standar untuk menegakkan diagnosis myxoma atrium kiri. Prinsip penatalaksanaan myxoma atrium kiri meliputi terapi medikamentosa terhadap kondisi yang menyertai dan terapi definitif dengan ekstirpasi tumor.
\end{abstract}

(J Kardiol Indones. 2015;36:28-33)

Kata kunci: myxoma atrium, ekokardiografi, ekstirpasi

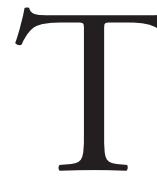

umor primer jantung merupakan penyakit yang langka. Insiden tumor jantung antara $0.0017 \%$ hingga $0.19 \%$ pasien pada otopsi. ${ }^{1}$

ma atrium kiri merupakan tumor jinak jantung yang paling banyak ditemui. ${ }^{2}$ Myxoma atrium kiri terjadi secara sporadis dan penyebabnya masih belum diketahui. Sepuluh persen myxoma atrium kiri berhubungan dengan faktor genetik (familial), sedangkan $90 \%$ myxoma atrium kiri masih belum diketahui etiologinya. ${ }^{3,4}$ Myxoma atrium kiri paling banyak ditemukan pada perempuan. ${ }^{5}$ Pertumbuhan myxoma atrium kiri bervariasi dari tidak bertambah

\footnotetext{
Alamat Korespondensi

dr. Prima Almazini Departemen Kardiologi dan Kedokteran Vaskular dan Pusat Jantung Nasional Harapan Kita, Jakarta. E-mail: pri_zz@ yahoo.com
}

besar hingga penambahan diameter sebesar 1,3-6,9 mm per bulan. ${ }^{6}$

Presentasi klinis myxoma atrium bergantung pada lokasi, ukuran, dan mobilitasi tumor. Presentasi klinis myxoma atrium kiri dapat bervariasi dari mulai asimtomatik hingga kematian mendadak. Gejala dan tanda myxoma atrium kiri dapat menyerupai berbagai penyakit. Myxoma atrium kiri sering salah didiagnosis sebagai stroke, endokarditis infektif, aritmia, atau penyakit katup jantung. ${ }^{7}$ Sebagian besar kasus myxoma atrium kiri ditegakkan melalui anamnesis dan pemeriksaan fisik yang mendalam serta dikonfirmasi dengan pemeriksaan ekokardiografi sebagai baku standar diagnosis myxoma atrium kiri. Tata laksana myxoma atrium kiri bergantung pada kondisi klinis yang menyertai dan pembedahan sebagai terapi definitif. Tulisan ini berfokus pada patofisiologi, diagnosis dan tata laksana myxoma atrium kiri. 


\section{Ilustrasi Kasus}

Seorang perempuan, 34 tahun, datang dengan keluhan sesak napas yang dirasakan 5 bulan dan memberat satu bulan sebelum masuk rumah sakit. Terdapat keluhan ortopnea dan paroxysmal nocturnal dyspnea (PND). Sesak napas memberat saat pasien miring ke kiri dan pasien merasa lebih baik saat miring ke kanan. Pasien mengalami penurunan berat badan sekitar 20 $\mathrm{kg}$ dalam 5 bulan.

Pasien tidak mengeluh nyeri dada, berdebar, maupun demam. Tidak terdapat riwayat hipertensi, diabetes mellitus dan dislipidemia. Tidak terdapat riwayat keluarga pasien yang menderita penyakit myxoma atrium kiri. Pasien sudah menikah dan memiliki 2 orang anak berusia 13 tahun dan 6 tahun. Kedua anak pasien lahir spontan dan normal. Pasien dirujuk dari Rumah Sakit Umum Daerah Karawang ke Rumah Sakit Jantung dan Pembuluh Darah Harapan Kita (RSJPDHK) dengan diagnosis myxoma atrium kiri.

Pada pemeriksaan fisik didapatkan takikardia dan tanda vital lain normal. Pemeriksaan antropometri didapatkan status gizi obesitas dengan berat badan $66 \mathrm{~kg}$, tinggi badan $150 \mathrm{~cm}$, dan indeks massa tubuh $29,3 \mathrm{~kg} / \mathrm{m}^{2}$. Terdapat peningkatan tekanan vena jugularis $5+4 \mathrm{cmH}_{2} \mathrm{O}$. Pemeriksaan auskultasi paru didapatkan ronki basah halus di satu pertiga basal bilateral paru, tidak terdapat mengi. Pemeriksaan auskultasi jantung didapatkan bunyi jantung dua mengeras, pansistolik murmur derajat $3 / 6$ di batas sternum kiri bawah menjalar ke apeks jantung, tumor plop, tidak didapatkan bunyi gallop pada auskultasi. Pada abdomen didapatkan hepatomegali 3 jari dibawah arkus kosta dengan bunyi usus normal di seluruh kuadran abdomen. Terdapat edema pretibial pada ekstremitas. Pemeriksaan neurologis dalam batas normal.

Pemeriksaan elektrokardiografi memperlihatkan irama sinus, gelombang P mitral, pola RSR pada V2, gelombang Q di III dan V1, dan blok atrioventrikel derajat I (Gambar 1). Pemeriksaan foto roentgen memperlihatkan kardiomegali (67\%), kontur ganda, dan tanda-tanda kongesti (Gambar 2). Pemeriksaan laboratorium dalam batas normal.

Ekokardiografi transtorakal memperlihatkan dimensi atrium kiri $63 \mathrm{~mm}$, dimensi ventrikel saat akhir diastolik $34 \mathrm{~mm}$, dimensi ventrikel saat akhir sistolik $23 \mathrm{~mm}$, fungsi ventrikel baik, fraksi ejeksi $51 \%$, penurunan fungsi ventrikel kanan, Tricuspid Annular Plane Systolic Excursion (TAPSE) $0.8 \mathrm{~cm}$,

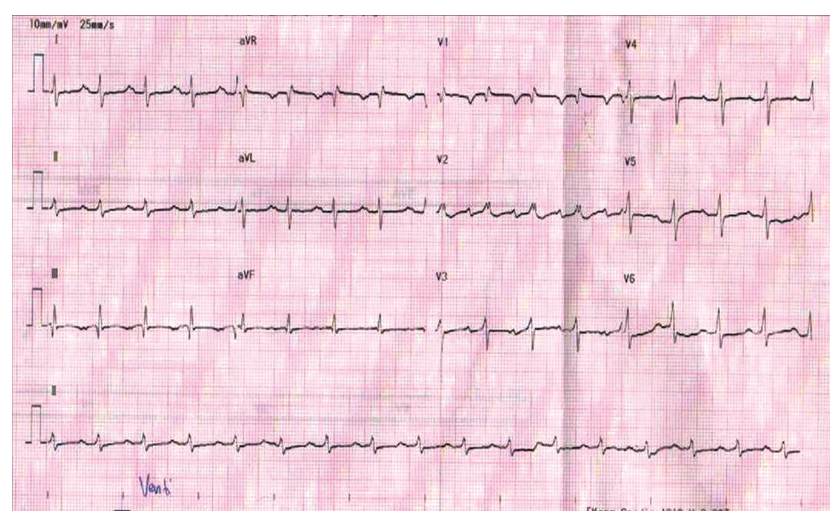

Gambar 1. Pemeriksaan elektrokardiografi di Unit Gawat Darurat (UGD)RSJPDHK

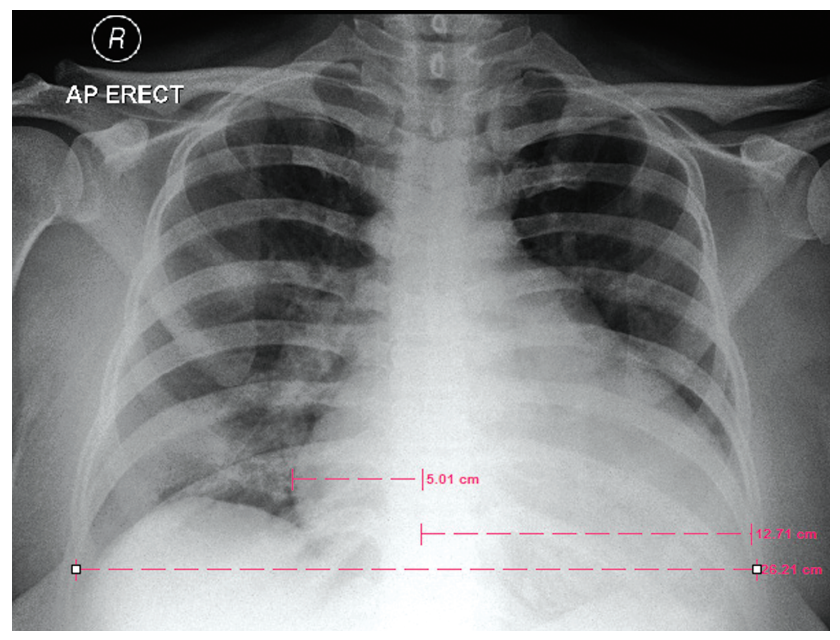

Gambar 2. Foto roentgen di UGD RSJPDHK

septum intraventrikel paradoks, regurgitasi katup aorta ringan, regurgitasi katup mitral ringan karena myxoma atrium kiri, regurgitasi katup trikuspid sedang sampai berat, regurgitasi katup pulmonal ringan, dan efusi perikardium minimal. Tampak massa atrium kiri dengan diameter $2,7 \times 5,9 \mathrm{~cm}$, melekat ke dinding anterior atrium kiri, prolaps ke ventrikel kiri melalui katup mitral saat fase diastolik (Gambar 3).

Pasien didiagnosis sebagai myxoma atrium kiri dengan gagal jantung kanan, regurgitasi katup mitral ringan, regurgitasi katup trikuspid sedang sampai berat, hipertensi pulmonal berat, dan efusi perikardium. Pasien diberikan terapi gagal jantung meliputi furosemid $2 \times 20 \mathrm{mg}$ intravena, ramipril mulai $1 \times 2,5 \mathrm{mg}$, dan spironolakton $1 \times 12,5 \mathrm{mg}$, Pasien tidak menjalani pemeriksaan koroangiografi. Pasien dijadwalkan untuk menjalani operasi segera. 


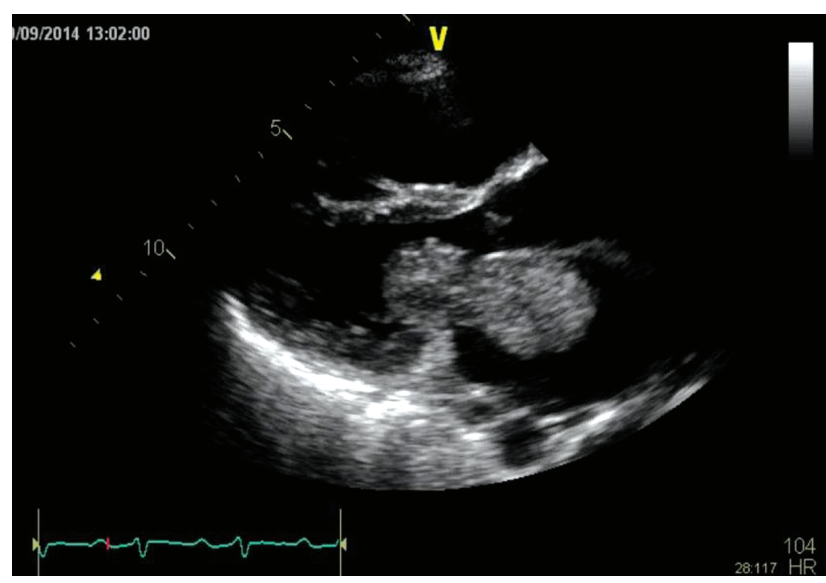

Gambar 3. Ekokardiografi transtorakal. Pandangan parasternal long axis memperlihatkan massa di atrium kiri menempel ke dinding anterior atrium kiri, menonjol ke katup mitral pada fase diastolik.

Tindakan ekstirpasi myxoma atrium kiri berhasil dilakukan menggunakan alat pintas jantung paru. Alat pintas jantung paru dibuat melalui kanula ke aorta asenden, vena kava superior, dan vena kava inferior. Dilakukan eksisi pada atrium kanan, septum interatrial dibuka, dan didapatkan massa di ruang atrium kiri. Saat operasi, ditemukan jantung yang membesar, dilatasi anulus katup trikuspid, dan myxoma atrium kiri bertangkai dengan diameter $5 \mathrm{~cm} \times 6 \mathrm{~cm} \times 5$ $\mathrm{cm}$.

Oleh karena anulus katup trikuspid membesar, dilakukan perbaikan katup trikuspid dengan prosedur Kay. Post operasi, pasien tidak mengalami komplikasi. Saat tindak lanjut, pasien tidak ada keluhan.

\section{Diskusi}

\section{Patofisiologi}

Pergerakan myxoma di ruang atrium berhubungan dengan perubahan spesifik pada hemodinamik atrium. Myxoma atrium tipe 1, bergerak dari ventrikel kiri ke atrium kiri pada awal fase sistolik dan dari atrium kiri ke ventrikel kiri pada fase diastolik, menyebabkan penonjolan gelombang $\mathrm{c}$ dan $\mathrm{v}$ diikuti oleh penurunan cepat gelombang $\mathrm{y}$. Myxoma atrium tipe 2, tetap di atrium kiri selama seluruh siklus jantung, menghambat aliran melalui katup mitral. Gelombang y menjadi lambat dan tidak dapat dibedakan dengan yang disebabkan oleh stenosis katup mitral. ${ }^{8}$ Pada pasien ini, pemeriksaan ekokardiografi memperlihatkan tumor prolaps ke ventrikel pada fase diastolik (Myxoma atrium tipe 1).

Pada myxoma atrium tipe 1 , tumor menyumbat lubang katup mitral seperti gerakan piston, pertama mendorong darah ke ventrikel kemudian menutup lubang katup mitral. Volume darah dan tumor yang masuk ke ventrikel menyebabkan bunyi jantung 3, yang disebut tumor plop. Adanya volume darah yang terlepas dari atrium kiri menyebabkan penurunan gelombang y yang mendadak pada tekanan atrium kiri. $^{8}$

Pergerakan myxoma atrium kiri yang besar dan bertangkai memberikan efek pada hemodinamik. Bunyi jantung tumor plop terdengar saat awal fase diastolik bersamaan dengan ekskursi maksimal tumor di traktus masuk ventrikel kiri. Pergerakan tumor selama pertengahan sampai akhir fase diastolik bertanggung jawab terhadap osilasi frekuensi rendah pada tekanan ventrikel kiri. Ekspulsi tumor dari ventrikel kiri ke atrium kiri dimulai saat kontraksi isovolumetrik dan berlanjut hingga awal fase ejeksi sistolik. Penutupan katup mitral menjadi terlambat sampai setelah onset ejeksi aorta dan ejeksi sistolik dimulai sebelum koaptasi katup mitral. ${ }^{9} 10$

Beberapa mekanisme mendasari bagaimana myxoma atrium kiri menyebabkan berbagai gejala. Obstruksi sirkulasi melalui jantung atau katup jantung menyebabkan gejala gagal jantung. Myxoma atrium mengganggu pergerakan katup menyebabkan regurgitasi. Invasi langsung terhadap miokardium menyebabkan gangguan kontraktilitas, aritmia, blok jantung, atau efusi perikardium dengan atau tanpa tamponade. Invasi terhadap jaringan paru terdekat menyebabkan gejala paru dan dapat menyerupai karsinoma bronkogenik. Myxoma atrium kiri akan melepaskan fragmen tumor atau trombus ke sirkulasi sistemik menyebabkan embolisasi sistemik maupun pulmonik. Komplikasi yang paling serius dari embolisasi adalah kelainan neurologis. Pada pasien ini, terdapat blok jantung dan efusi perikardium disebabkan oleh invasi langsung miokardium oleh tumor. ${ }^{4}$

\section{Diagnosis}

\section{Anamnesis}

Presentasi klinis myxoma atrium kiri dibagi menjadi 3 gejala, yaitu gejala obstruksi kardiak (67\%), sistemik 
(34\%), dan emboli (29\%). Gejala obstruksi kardiak meliputi sesak napas, gagal jantung, mengantuk, sinkop karena obstruksi katup mitral. Gejala konstitusional meliputi gejala autoimun, vaskulitis, penurunan berat badan, demam, dan gejala nonspesifik lain. Gejala emboli, yang paling sering emboli serebral. Myxoma atrium kiri menimbulkan gejala apabila beratnya sudah lebih dari 70 gram.

Pasien ini mengalami gejala sesak napas, ortopnea, dan PND disertai edema pretibial. Sesak napas pada pasien semakin memberat dengan perubahan posisi miring ke kiri. Hal ini karena adanya perubahan posisi tumor di dalam atrium. Pasien juga mengalami gejala konstitusional berupa penurunan berat badan. Penyebab gejala konstitusional masih belum jelas. Beberapa penelitian menyatakan sitokin interleukin-6 berperan pada timbulnya gejala konstitusional, namun hal ini masih kontroversial. ${ }^{11}$

Pada pasien ini gejala dan tanda gagal jantung merupakan konsekuensi obstruksi intrakardiak disebabkan oleh massa di ruang atrium kiri. Obstruksi parsial aliran masuk mitral menyebabkan dilatasi ruang atrium kiri, gejala kongesti paru, hipertensi pulmonal, dan gagal jantung kanan. Dilatasi ventrikel kanan menyebabkan dilatasi anulus katup trikuspid dan menyebabkan regurgitasi katup trikuspid.

\section{Pemeriksaan Fisik}

Pada myxoma atrium kiri didapatkan tanda gagal jantung seperti peningkatan tekanan vena jugular, bunyi ronki basah halus pada auskultasi paru, hepatomegali, dan edema pretibial. Myxoma atrium kiri menghasilkan bunyi diastolik yang disebut tumor plop. Pada pasien ini, bunyi jantung 2 yang mengeras disebabkan oleh hipertensi pulmonal dan murmur pansistolik disebabkan oleh regurgitasi katup trikuspid.

Bunyi tumor plop terdengar pada awal fase diastolik. Bunyi tumor plop dihasilkan oleh obstruksi aliran masuk ventrikel yang terjadi karena tumor menutupi anulus katup mitral. Meskipun sama dengan waktu stenosis katup mitral, tumor plop berbeda dengan bunyi opening snap katup mitral pada mitral stenosis. Bunyi jantung tumor plop merupakan bunyi frekuensi rendah dan paling baik terdengar dengan permukaan bel stetoskop. ${ }^{12}$ Bunyi tumor plop terdengar lebih spesifik untuk diagnosis myxoma atrium kiri tetapi hanya terdapat pada $15 \%$ kasus.

\section{Ekokardiografi}

Ekokardiografi dua dimensi merupakan alat noninvasif yang akurat untuk evaluasi awal. Ekokardiografi dua dimensi dapat menilai morfologi, lokasi, dan gerakan tumor serta konsekuensi hemodinamik tumor. Pada ekokardiogram, myxoma atrium kiri biasanya tampak sebagai massa bergerak yang menempel pada permukaan endokardial, yang berasal dari fossa ovalis. Gambaran ekokardiografi klasik myxoma yaitu massa halus bergerak menempel ke septum interatrial melalui tangkai yang menyebabkan tumor prolaps ke ventrikel kiri selama fase diastolik. ${ }^{13}$

Massa sering terlihat sebagai bentuk ireguler ditandai dengan jaringan yang berbenjol-benjol atau gambaran seperti anggur. Ekogenisitas massa terlihat tidak homogen dan kadang-kadang terlihat area kalsifikasi. Pada pasien ini, myxoma atrium kiri menempel ke interatrial septum tanpa kalsifikasi. Pada pasien ini tidak dilakukan TEE karena tujuan pemeriksaan ekokardiografi pada myxoma atrium sudah tercapai dengan pemeriksaan TTE.

Angiografi koroner merupakan alat diagnostik yang berguna untuk mengevaluasi vaskularitas tumor dan menyingkirkan penyakit arteri koroner. Angiografi koroner harus dilakukan pada seluruh pasien di atas umur 40 tahun. Neovaskularisasi terlihat pada $80 \%$ pasien dengan myxoma atrium kiri. ${ }^{14}$ Pasien ini berumur kurang dari 40 tahun sehingga tidak dilakukan pemeriksaan koroangiografi.

\section{Terapi}

Satu-satunya terapi definitif untuk myxoma atrium kiri adalah ekstirpasi tumor. Pembedahan harus dilakukan sesegera mungkin. Pemilihan waktu pembedahan bergantung pada keadaan umum pasien, kondisi medis yang menyertai, dan ketersediaan dokter bedah. Terapi medikamentosa diberikan untuk mengobati kondisi yang menyertai seperti aritmia, gagal jantung, dan emboli. Aritmia ditangani dengan obat aritmia sampai operasi dapat dilakukan. Apabila terdapat gagal jantung residual pascaoperasi, terapi gagal jantung diberikan dalam jangka panjang.

Hasil pembedahan pada kasus myxoma atrium kiri sangat baik tanpa morbiditas mayor dan dengan survival jangka menengah sama dengan populasi umum. Namun, dari beberapa studi sebelumnya (berjumlah 30-70 pasien) telah dilaporkan memiliki tingkat mortalitas perioperatif 3-4\% dan komplikasi 
operasi yang mayor adalah stroke, tamponade jantung, dan gagal napas. ${ }^{1}$ Meskipun myxoma atrium merupakan tumor jinak, jika tidak diberikan penanganan yang tepat, sinkop dan bahkan kematian mendadak dapat terjadi karena tumor dapat menutup lubang katup mitral dan menghambat aliran darah ke ventrikel kiri.

Operasi myxoma atrium kiri dapat dilakukan dengan hasil yang memuaskan bahkan apabila dikombinasikan dengan prosedur tambahan seperti bedah katup atau revaskularisasi koroner. Pembedahan dilakukan segera setelah diagnosis ditegakkan untuk mencegah komplikasi seperti emboli perifer atau obstruksi katup jantung. Prognosis jangka panjang dan jangka pendek sangat baik dan rekurensi jarang terjadi, meskipun demikian pemeriksaan ekokardiografi enam bulan setelah operasi direkomendasikan pada seluruh kasus. Pada pasien ini, operasi dilakukan sesegera mungkin setelah diagnosis ditegakkan dengan ekokardiografi. Pembedahan pada pasien ini dilakukan bersamaan dengan perbaikan katup trikuspid.

\section{Ringkasan}

Pasien perempuan, 34 tahun, datang ke rumah sakit dengan presentasi klinis gagal jantung. Pada pemeriksaan fisik memperlihatkan tanda kongesti dan terdapat bunyi jantung tumor plop. Pemeriksaan ekokardiografi memperlihatkan gambaran klasik ekokardiografi myxoma atrium kiri yaitu tampak massa atrium kiri yang menempel di septum atrium yang prolaps ke ventrikel pada saat diastolik. Sebelum operasi, pasien telah diobati dengan terapi gagal jantung sampai waktu pembedahan. Gejala kongesti pasien mengalami perbaikan. Pasien dilakukan operasi ekstirpasi dan perbaikan katup trikuspid sebagai terapi definitif dalam 5 hari setelah diagnosis ditegakkan. Hasil operasi sangat baik, pasien tidak ada keluhan paska operasi maupun saat tindak lanjut.

\section{Daftar Pustaka}

1. Yu K, Liu Y, Wang H, Hu S, Long C. Epidemiological and pathological characteristics of cardiac tumors: a clinical study of 242 cases. Interact Cardiovasc Thorac Surg. 2007;6(5):636639.

2. Amano J, Kono T, Wada Y, Zhang T, Koide N, Fujimori M, Ito K. Cardiac myxoma: its origin and tumor characteristics. Ann Thorac Cardiovasc Surg. 2003;9(4):215-221.

3. Butany J, Nair V, Naseemuddin A, Nair GM, Catton C, Yau T. Cardiac tumours: diagnosis and management. Lancet Oncol 2005;6:219-228.

4. Vazir and Douthwaite: Rapidly growing left atrial myxoma: a case report. Journal of Medical Case Reports 2011 5:417.

5. Aggarwal SK, Barik R, Sarma TC, Iyer VR, Sai V, Mishra J, Voleti CD. Clinical presentation and investigation findings in cardiac myxomas: new insights from the developing world. Am Heart J. 2007;154(6):1102-1107.

6. Iga K, Izumi C, Konishi T: Rapid growth of a left atrial myxoma. Serial two dimensional echocardiographic observation over eighteen months. Int J Cardiol 1997, 61:85-87.

7. O'sRourke F, Dean N, Mouradian MS, Akhtar N, Shuaib A: A trial myxoma as a cause of stroke: case report and discussion. JAMC 2003, 169:10.

8. Pinede L, Duhaut P, Loire R. Clinical presentation of left atrial cardiac myxoma. A series of 112 consecutive cases. Medicine (Baltimore) 2001;80:159-72.

9. Sung RJ, Ghahramani AR, Mallon SM, Richter SE, Sommer LS, Gottlieb S, Myerburg RJ. Hemodynamic features of prolapsing and nonprolapsing left atrial myxoma. Circulation. 1975 Feb;51(2):342-9.

10. Cox WR, Damore S, Rubal BJ, Murgo JP. Left atrial myxoma: phonocardiographic, echocardiographic, and micromanometric hemodynamic correlation. Circulation. 1975 Feb;51(2):342-9.

11. Mendoza CE, Rosado MF, Bernal L. The role of interleukin-6 in cases of cardiac myxoma: clinical features, immunologic abnormalities, and a possible role in recurrence. Tex Heart Inst J. 2001;28:3e7.

12. Kolluru A, Desai D, Cohen GI. The etiology of atrial myxoma tumor plop. J Am Coll Cardiol. 2011;57(21):e371.

13. Yoo M, Graybeal DF. An echocardiographic-confirmed case of atrial myxoma causing cerebral embolic ischemic stroke: a case report. Cases J. 2008;1(1):96.

14. Reynen K. Cardiac myxomas. New Engl J Med 1995; 333:1610-7.

15. Rahmanian PB, Castillo JG, Sanz J, Adams DH, Filsoufi F. Cardiac myxoma: preoperative diagnosis using a multimodal imaging approach and surgical outcome in a large contemporary series. Interact Cardiovasc Thorac Surg. 2007;6(4):479-483. 